\title{
Factors Promoting Increased Rate of Tissue Regeneration: The Zebrafish Fin as a Tool for Examining Tissue Engineering Design Concepts
}

\author{
Vijay P. Boominathan and Tracie L. Ferreira
}

\begin{abstract}
Student interest in topics of tissue engineering is increasing exponentially as the number of universities offering programs in bioengineering are on the rise. Bioengineering encompasses all of the STEM categories: Science, Technology, Engineering, and Math. Inquiry-based learning is one of the most effective techniques for promoting student learning and has been demonstrated to have a high impact on learning outcomes. We have designed program outcomes for our bioengineering program that require tiered activities to develop problem solving skills, peer evaluation techniques, and promote team work. While it is ideal to allow students to ask unique questions and design their own experiments, this can be difficult for instructors to have reagents and supplies available for a variety of activities. Zebrafish can be easily housed, and multiple variables can be tested on a large enough group to provide statistical value, lending them well to inquiry-based learning modules. We have designed a laboratory activity that takes observation of fin regeneration to the next level: analyzing conditions that may impact regeneration. Tissue engineers seek to define the optimum conditions to grow tissue for replacement parts. The field of tissue engineering is likely to benefit from understanding natural mechanisms of regeneration and the factors that influence the rate of regeneration. We have outlined the results of varying temperature on fin regeneration and propose other inquiry modules such as the role of $\mathrm{pH}$ in fin regeneration. Furthermore, we have provided useful tools for developing critical thinking and peer review of research ideas, assessment guidelines, and grading rubrics for the activities associated with this exercise.
\end{abstract}

\section{Introduction}

A S EARLY AS THE 1920's, John Dewey outlined the benefits of experiential learning. Dewey's observation: "give the pupils something to do, not something to learn; and the doing is of such a nature as to demand thinking; learning naturally results." Dewey's theory of experience has been the foundation for experiential learning techniques for nearly a century. ${ }^{1}$ In science, we know that our concepts cannot be taught by lectures alone, which is why most science classes have incorporated laboratory sections. Our scientific training in $\mathrm{K}-16$ routinely includes carrying out experiments, and for decades we have become efficient in designing concise well-planned activity modules for our laboratory sessions. We have now progressed from merely facilitating "hands-on experiences" in the laboratory to inquiry-based science instruction. Minner et al. ${ }^{2}$ utilized data from more than 100 studies and found that inquiry-based approaches in the sciences made the greatest positive difference, when there was an emphasis on active learning and involvement in the investigative process. The investigative process was defined as: asking questions, designing investigations, collecting data, drawing conclusions, and communicating findings. ${ }^{2}$ In other words, allow students to ask a question, then allow the students time to design the experiments to answer the questions.

\section{Tissue engineering challenges}

Engaging students in experiments that involve current hot topics in the world is one of the best ways to promote interest in scientific discovery. One of the most exciting and controversial topics in science and politics is stem cell research, and the desire of scientists to be able to regenerate human tissues and organs. Our bodies begin as a single totipotent stem cell that has the potential to become any cell type in the body. ${ }^{3}$ When scientists attempt to regenerate tissue in a laboratory, they need three things: a good source of cells that have the potential to become the desired tissue, ${ }^{4}$ a scaffold or source of

Department of Bioengineering, University of Massachusetts, North Dartmouth, Massachusetts. 
housing for the cells so they can grow and differentiate, and a healthy environment that mimics the natural biological environment of the body. In tissue engineering, the environment for tissue growth is established in bioreactors. ${ }^{5}$ Environmental factors influencing cell growth and differentiation include temperature, ample nutrients, and appropriate $\mathrm{pH}$. These concepts are often complex and difficult to integrate into functional models for tissue engineering. However, as we transition to more dynamic, inquiry-based science teaching, we have outlined a method in which these complex concepts can be examined in the laboratory. The exercise outlined in this report can help students to understand the physiological effect of "poor" environment on cell function. Fin regeneration is a useful, measurable outcome to analyze these variables.

\section{Fin regeneration}

Zebrafish regenerate numerous structures such as the spinal cord, optic nerve, heart, and fins. ${ }^{6}$ The fin is the preferred model for studying regeneration, due to its easy access and structural simplicity. Amputation of the fin is a simple procedure and can be performed on multiple fish, allowing for modules that include statistical analysis. Most importantly, the fish continue to survive normally without the fin and rapidly regenerate it, allowing for a dramatic outcome over the course of one week. There are two major stages that occur during fin regeneration: wound healing, which is completed within the first 12 hours, and then tissue outgrowth. ${ }^{7-10} \mathrm{Nu}$ merous studies ${ }^{11-14}$ have examined fin regeneration, and many reviews are available promoting fruitful student literature searches aiding in the composition of detailed introductions in their lab reports.

We have taken advantage of the zebrafish model to teach our freshmen bioengineering students the concepts behind cellular activity and the impact of external factors on this biological process. We have incorporated potential variables that are relevant to tissue engineering and potential concepts to consider in regards to bioreactor design. We chose temperature because temperature controls the rate of chemical and enzymatic processes occurring within the wound and the metabolism of cells and tissue engaged in the repair process. It is known that frequent dressing changes or cleaning the wound with room temperature solutions can cause a drop in temperature that takes several hours to restore to physiological levels. Therefore, students pose the question: how does the temperature affect healing and regeneration? Additional concepts to explore could include nutritional health, as well as $\mathrm{pH}$, because these will also affect regeneration and are easily manipulated during the course of the experiment.

\section{Learning outcomes and critical thinking skill development}

All educational institutions strive to provide continuous improvement in their programs. The need for consistent evaluation is particularly important in the sciences because of the dynamic nature of the field. As courses are developed, and laboratory components are developed, it is helpful that educational objectives are considered. Ultimately, course assessment should determine what individual students are learning and how well they are learning it. As an engineering program, we are charged with 11 specific student outcomes $(A-K)$, as outlined by The Accreditation Board for Engineering and Technology (ABET). This first semester freshman lab activity addresses 4 of these outcomes: B. An ability to design and conduct experiments, as well as to analyze and interpret data; D. An ability to function on teams; F. An understanding of professional and ethical responsibility; and G. An ability to communicate effectively. The teamwork and experimental design outcomes are addressed in our research proposal activity, ethics are covered in training activity for handling of vertebrate animals as per IACUC guidelines, and ability to conduct an experiment and analyze data is clearly demonstrated during the numerous data gathering and analysis sessions. These program outcomes are similar to outcomes for science programs across disciplines, making this activity useful in for numerous courses ranging from bioengineering, developmental biology, or general biology.

\section{Materials and Methods}

\section{Maintenance of zebrafish}

Zebrafish were maintained in the UMass Dartmouth Zebrafish Facility, essentially as described in The Zebrafish Book. ${ }^{15}$ Wild-type $\mathrm{AB}^{*}$ fish were used. Care was taken to use age and size matched fish to limit variability from these factors. Three one-gallon tanks (Petco, Inc.) were individually maintained in the fish room on the bench top with individual heaters and thermometers. The tanks were maintained for temperatures $30^{\circ} \mathrm{C}, 28^{\circ} \mathrm{C}$, and room temperature (RT), which varied between $26^{\circ}-27^{\circ} \mathrm{C}$ throughout the study. Temperature was recorded twice a day, once by a student and at the end of the day by the professor. Fin measurements were obtained on the $2^{\text {nd }}$, $3^{\text {rd }}$, and $6^{\text {th }}$ day post amputation (dpa).

\section{Experiment proposal design}

Day 1. Students received an in-class 30 minute lecture highlighting the zebrafish anatomy, regenerative potential, and general outline of stages of wound healing and fin regeneration. ${ }^{16,17}$ The second part of the lecture highlighted factors that must be considered during tissue engineering experiments. This allowed for integration of this model into our course for bioengineers. At the conclusion of the lecture, the students were given a tour of the zebrafish facility and laboratory and were shown what resources were available for experiments.

Task 1. Student design of experiments to test the effect of variables on fin regeneration. The cohort of 24 first semester freshmen students were divided into 8 separate groups of three students. The students were assigned group numbers and proposals were numbered to maintain anonymity during peer review. The students were charged with meeting outside of class to formulate a testable hypothesis of a variable that may impact fin regeneration. They were required to assemble a "proposal" outlining their ideas (Appendix 1).

\section{Day 2: Proposal peer review.}

Task 2. Three proposals for evaluation were distributed to each student. Three were chosen because this is typical external grant review procedure and to ensure that students received varied feedback, since not all groups will be as effective in providing comments. The groups were given the entire lab session ( 2 hours) to perform their reviews and the evaluations were collected, copied, and results distributed for 
discussion in the next class (proposal scoring sheets, Appendix 1). After reviewing proposal scores and determining which experiment scored highest, we discussed the timeline for initial fin clip and data collection.

\section{Animal training}

The undergraduate activities described here were approved by the University of Massachusetts Animal Care and Use Committee (IACUC), protocol 11-13, assurance \#A449101. Prior to the fin amputation, the students completed a brief on-line training module modeled after the Collaborative Institutional Training Initiative (CITI) IACUC training resource. The goal of this module was to introduce the students to Animal Welfare and the 3 R's: Replacement, Reduction, and Refinement. Actual in-lab training on how to handle the animals was demonstrated by the professor, and each student was supervised at all times during the fin amputation and fin measurements.

Days 3-9. These days were experimental days and included fin amputation (Day 3 ) and measurements at 2, 3, and
6 dpa (Days 5-9), as described above. Students organized the schedule of times to measure fins each day, Day 6 was chosen because of our lab schedule. The amputation was on a Tuesday, leaving the following Monday as a Day 6 ending time point. The proposal suggested three time points for measurement.

\section{Fin amputation}

Amputations of zebrafish fins were carried out on Day 3 of the lab activity. Individual zebrafish were placed in a Petri dish with $4 \%$ Tricaine (sedative) until the fish was asleep which took approximately 2 minutes. Once immobile, the fish was moved to the dry lid of the Petri dish, oriented so the head was positioned to the left, the caudal fin was fanned out, and the lower fin was cut with a clean razor blade (Fig. 1). The fish was then transferred back to a tank of fresh water, observed for gill movement, and allowed to awaken. If there is concern with the revival of the fish, resuscitation is aided by flushing water through the gills gently with a plastic transfer pipette. Each student performed one fin amputation (24 students $=8$ (fish) $\times 3$ (temperatures).
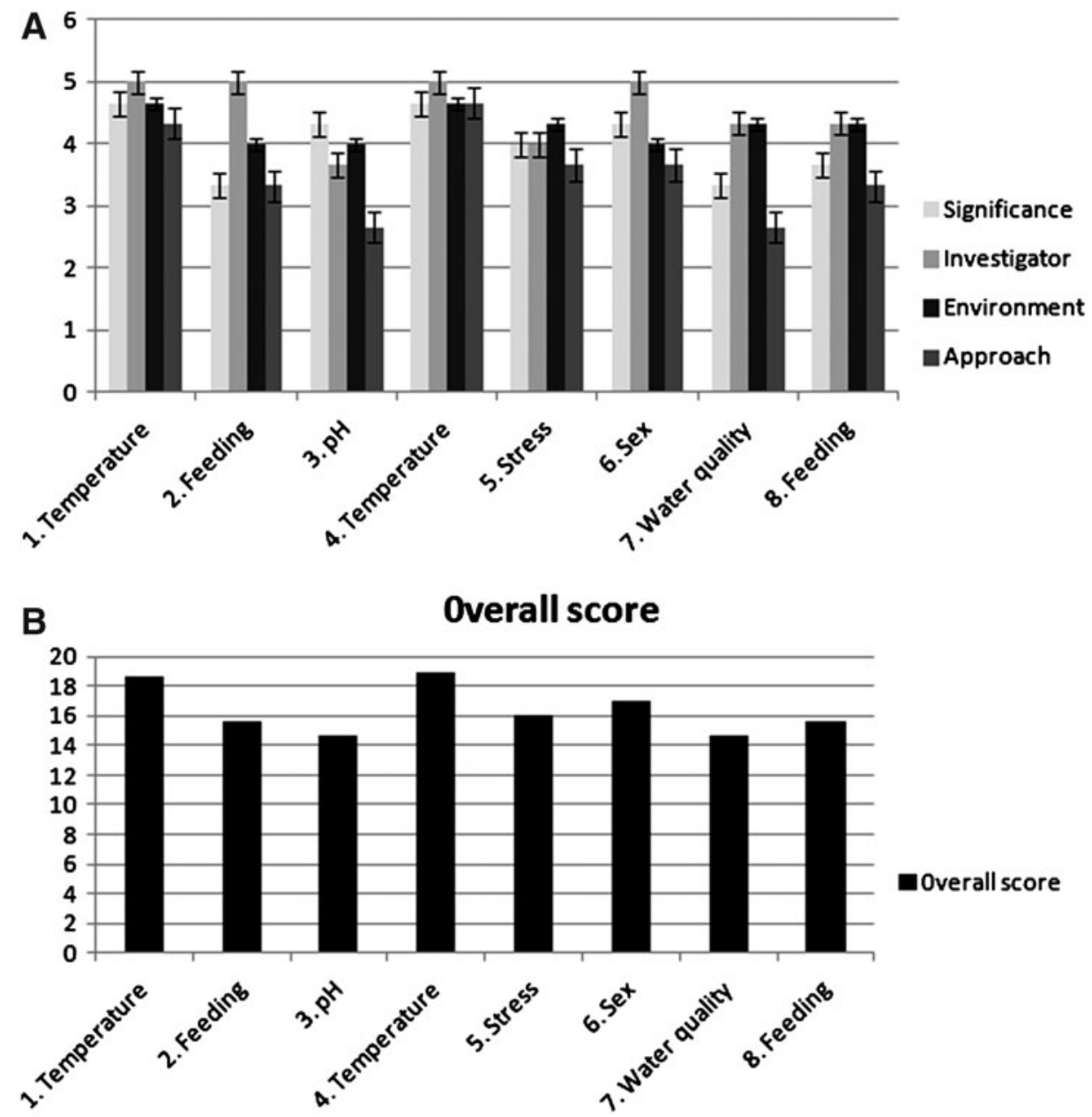

FIG. 1. (A) Student proposals were rated on a scale of 1-5 for Significance, Investigator, Environment, and Approach. Each of the eight proposals are shown, and the average rating in each category is included after three individual reviews were gathered for each proposal. A score of 5 indicated excellent, and ranked that proposal in the top 5\%. (B) The total overall numerical score was the sum of the four sections. This graph shows the average of the overall score based on the three individual reviews. 


\section{Fin measurement}

Students were assigned specific days to return throughout the week for fin measurement.. Each student measured multiple fish ensuring that all fish were measured on Days 2, 3, and 6 post amputation. Each fish was anesthetized in $4 \%$ Tricaine (as described above). The regenerated portion of the fin is transparent, allowing for easy identification upon imaging. All fish were placed in the same orientation and fins fanned out prior to imaging. The calibrated scale bar was used on each captured image; alternatively a ruler can be placed on the bottom of the fin allowing for measurement. Bright-field images were taken of each individual fin using the Olympus 12.5 megapixels color digital camera.

Day 10: Data analysis using Image-J. Each captured image was analyzed using the freely downloaded Image-J software (NIH.gov). Image-J is open source software for analyzing images with known parameters. It is written in Java and is user friendly, freely available on the web, compatible with Linux, Mac OS X, and Windows in both 32 and 64-bit modes and the fastest Java image processing program. The Image-J program is initiated and each image is opened into the program. The students easily set the scale based on the scale represented within the captured image. The total area was measured using the free-hand tool three times to obtain an average value, length of regeneration from point of amputation of individual fin rays was also measured in triplicate using the line tool and the average was recorded. Microsoft Excel (used here) or any other statistical software could be used for final data processing. All students entered data for their assigned fish into a common Excel sheet. The data were disseminated to each student and they used the raw data to generate graphs and determine significance. Using the measured data and calculated SD values, column/bar graphs are plotted with customized error bars of SD values. A Student $t$ test was also carried out for comparing the length/area of regeneration comparing $\mathrm{RT}-28^{\circ} \mathrm{C}, \mathrm{RT}-30^{\circ} \mathrm{C}$, and $28^{\circ}-30^{\circ} \mathrm{C}$, respectively. For using the Student $t$-test on Microsoft Excel, formulas can be used selecting appropriate data.

\section{Final assignment}

The final assignment was the generation of a well-ordered manuscript style lab report explaining the experimental outcome (Appendix 2, rubric). Briefly, the students were expected to generate a succinct abstract describing the hypothesis, prediction, and outcome. They were then expected to provide introductory material that explained the significance of this research, as well as explain fin regeneration and zebrafish biology. They were also expected to perform correct in-text citations of sources. The materials and methods section was straightforward. The most challenging component was the results and discussion. Students were required to present their results in logical order, being assigned specific figures and tables to include in this section. They were graded on their ability to label their figures effectively, on their ability to wrap text and incorporate the discussion close to the graph or image for the ease of the reader. They were also expected to include descriptive figure legends. Finally, the conclusion was expected to provide a brief summary of the project and exceptional ratings were given to students that were able to assemble the data and suggest future studies or discuss limitations of this study.

\section{Results}

\section{Designing a research hypothesis, team proposal development and peer review}

Days 1 and 2. Students received a lecture regarding zebrafish fin regeneration; this regeneration laboratory followed a laboratory experiment analyzing enzyme activity (Biofuel Enzyme Kit, BioRad, Hercules, CA). The Biofuel enzyme activity examined the kinetics of enzyme activity with variable conditions such as $\mathrm{pH}$ and temperature. This experimental kit is an excellent starting point for these discussions as they do not require complex equipment and introduce the students to concepts such as deriving a standard curve, using it to estimate activity levels and in calculating rates of reaction. Having performed the enzyme analyses, the students were asked to generate hypotheses regarding factors that may impact fin regeneration in the zebrafish model.

\section{Proposal development results}

The eight-student groups had proposals that examined five different topics. Duplicate proposal topics were temperature, feeding, and $\mathrm{pH} /$ water quality, while proposals examining stress or sex were generated by single student groups. Each proposal was reviewed by three peer groups, raw scores were reported as an average for each category, and an overall score for each category was generated (Fig. 1). The two proposals that evaluated temperature as a variable were scored the highest, and interestingly the "sex" proposal was the second highest scored proposal. The students tested the following hypothesis: "Warmer temperatures enable a higher rate of regeneration compared to colder temperatures" with a null hypothesis: "There is no difference in rate of regeneration with difference in temperature."

\section{Rate of fin regeneration using total area measurements}

All fish (8) in each temperature were imaged 2, 3, and 6 days post amputation. Each captured .tiff image was used for measurement in Image-J. The students performed three individual area measurements and calculated the average of those three measurements for the final area of regeneration for each fish on each day. Total area of regeneration was greater each day as temperature increased (Fig. 2A). When fins were displayed as a composite figure outlining area of regenerated tissue, there appeared to be a significant increase in area of regeneration with an increase in temperature (Fig. 3). The difference between room temperature (RT) and $28^{\circ} \mathrm{C}$ was not as pronounced as the difference between $\mathrm{RT}$ or $28^{\circ} \mathrm{C}$ and $30^{\circ} \mathrm{C}$. Statistical analysis revealed that the areas between RT and $28^{\circ} \mathrm{C}$ on Days 3 and 6 were indeed not significantly different (Table 1). When actual daily rates of regeneration were calculated, the $30^{\circ} \mathrm{C}$ fish showed an initial high rate of regeneration within the first 2 days $57,179 \mu \mathrm{m}^{2} /$ day when compared to $30,323 \mu \mathrm{m}^{2} /$ day and $21,544 \mu \mathrm{m}^{2} /$ day at $28^{\circ} \mathrm{C}$ and $\mathrm{RT}$, respectively (Table 2 ). This more rapid rate of regeneration continued through the 6 day experiment.

\section{Rate of fin regeneration using fin ray length measurements}

The students also collected values on the length of fin rays 2 and 3 at each time point. Three individual length 
A

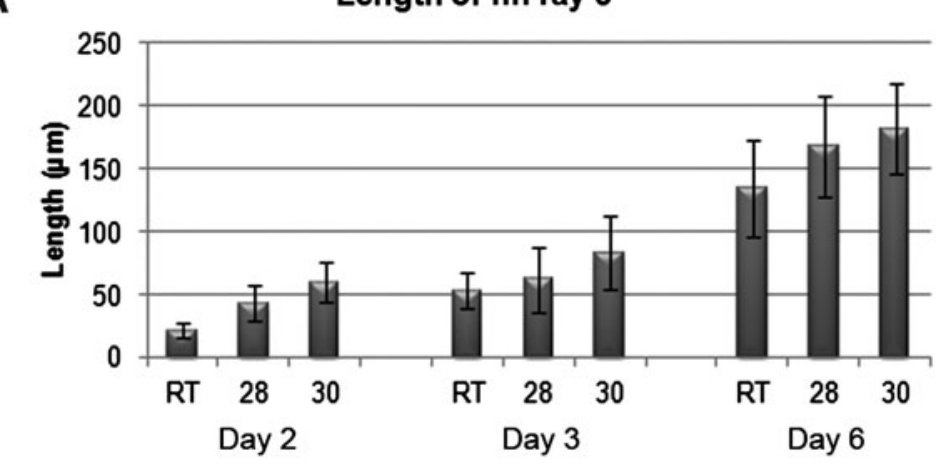

B

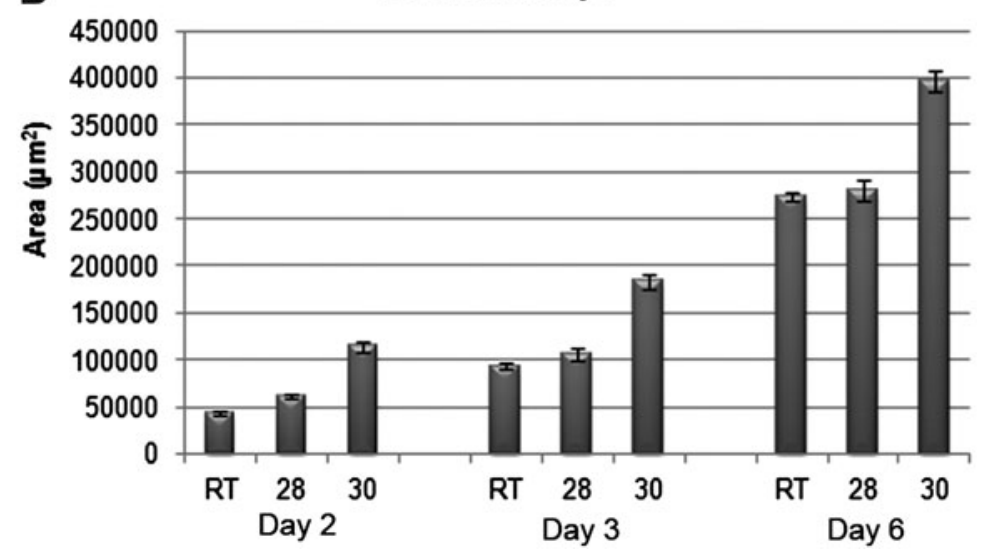

FIG. 2. (A) Total length of regeneration of fin ray 3 of fish housed at three temperatures over 6 days. Similar trends are seen measuring fin ray length as measuring total area. (B) Total area of fin regeneration of fish housed at three temperatures over 6 days. Minimal increase in regeneration is seen between $\mathrm{RT}$ and $28^{\circ} \mathrm{C}$, while a significant increase is seen between $\mathrm{RT} / 28^{\circ} \mathrm{C}$ and $30^{\circ} \mathrm{C}$.
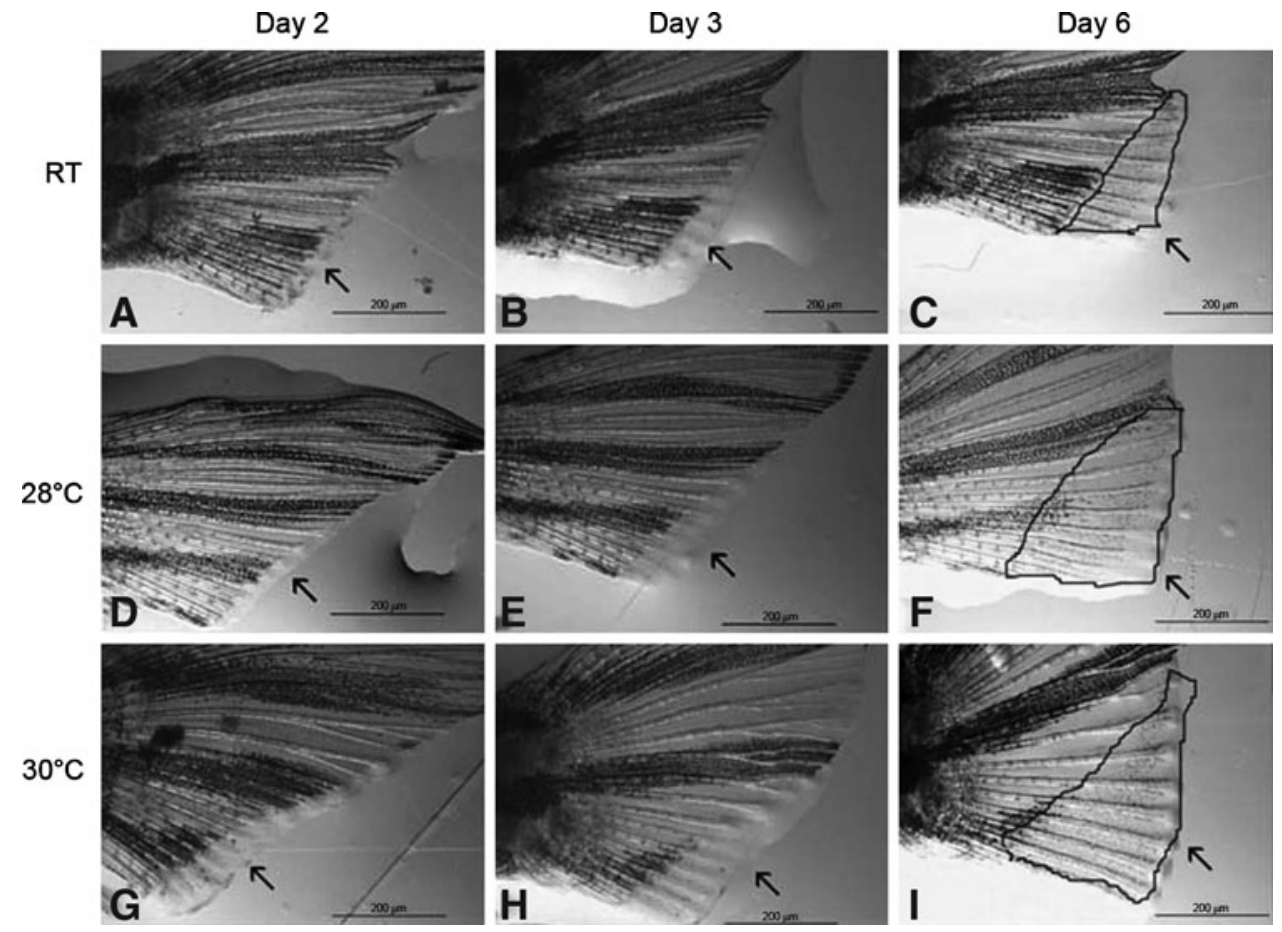

FIG. 3. Representative fish from each day and each temperature during the fin regeneration exercise. As early as 2 dpa, there is a dramatic increase in area of regeneration in the $30^{\circ} \mathrm{C}$ fish $(\mathrm{G})$ when compared to the $\mathrm{RT} / 28^{\circ} \mathrm{C}$ fish $(\mathbf{A}$ and $\mathbf{D})$. This trend continues throughout all time points measured, $3 \mathrm{dpa}(\mathbf{B}, \mathbf{E}$, and $\mathbf{H})$ and $6 \mathrm{dpa}(\mathbf{C}, \mathbf{F}$, and $\mathbf{I})$. Scale bars provided values for ImageJ measurements; dpa, days post amputation. 
Table 1. Student T-Test to Analyze the Statistical Significance. Analysis of Significance Using a One-Tail, Type 2,3 $T$-Test

\begin{tabular}{|c|c|c|c|c|c|c|c|}
\hline & \multirow[b]{2}{*}{ T-Test } & \multicolumn{2}{|c|}{ Day 2} & \multicolumn{2}{|c|}{ Day 3} & \multicolumn{2}{|c|}{ Day 6} \\
\hline & & $\begin{array}{c}\text { Equal } \\
\text { variance } \\
\mathrm{P} \text { value }\end{array}$ & $\begin{array}{l}\text { Unequal } \\
\text { variance } \\
\mathrm{P} \text { value }\end{array}$ & $\begin{array}{c}\text { Equal } \\
\text { variance } \\
\mathrm{P} \text { value }\end{array}$ & $\begin{array}{l}\text { Unequal } \\
\text { variance } \\
\mathrm{P} \text { value }\end{array}$ & $\begin{array}{c}\text { Equal } \\
\text { variance } \\
\mathrm{P} \text { value }\end{array}$ & $\begin{array}{l}\text { Unequal } \\
\text { variance } \\
\mathrm{P} \text { value }\end{array}$ \\
\hline RAY 2 & $\begin{array}{l}\text { RT vs } 28 \\
\text { RT vs } 30 \\
28 \text { vs } 30\end{array}$ & $\begin{array}{l}0.040053^{*} \\
0.000029^{* *} \\
0.037865^{*}\end{array}$ & $\begin{array}{l}0.050204 \\
0.004275^{* *} \\
0.039502^{*}\end{array}$ & $\begin{array}{l}0.197822 \\
0.009995^{* *} \\
0.026342^{*}\end{array}$ & $\begin{array}{l}0.198133 \\
0.011679^{*} \\
0.081848^{*}\end{array}$ & $\begin{array}{l}0.140151 \\
0.011594^{*} \\
0.081814^{*}\end{array}$ & $\begin{array}{l}0.140180 \\
0.011679^{*} \\
0.081848^{*}\end{array}$ \\
\hline RAY 3 & $\begin{array}{l}\text { RT vs } 28 \\
\text { RT vs } 30 \\
28 \text { vs } 30\end{array}$ & $\begin{array}{l}0.012860^{*} \\
0.000013^{* *} \\
0.002422^{* *}\end{array}$ & $\begin{array}{l}0.151104 \\
0.006292^{* *} \\
0.047947^{*}\end{array}$ & $\begin{array}{l}0.148217 \\
0.004299^{* *} \\
0.002422^{* *}\end{array}$ & $\begin{array}{l}0.151104 \\
0.006292^{* *} \\
0.047947^{*}\end{array}$ & $\begin{array}{l}0.177740 \\
0.006199^{* *} \\
0.040876^{*}\end{array}$ & $\begin{array}{l}0.177748 \\
0.006226^{* *} \\
0.040992^{*}\end{array}$ \\
\hline AREA & $\begin{array}{l}\text { RT vs } 28 \\
\text { RT vs } 30 \\
28 \text { vs } 30\end{array}$ & $\begin{array}{l}0.037325^{*} \\
0.001495^{* *} \\
0.003158^{* *}\end{array}$ & $\begin{array}{l}0.037421^{*} \\
0.001195^{* *} \\
0.005531^{* *}\end{array}$ & $\begin{array}{l}0.241039 \\
0.000974^{* *} \\
0.006529^{* *}\end{array}$ & $\begin{array}{l}0.285500 \\
0.002571^{* *} \\
0.008494^{* *}\end{array}$ & $\begin{array}{l}0.436149 \\
0.001198^{* *} \\
0.008487^{* *}\end{array}$ & $\begin{array}{l}0.436817 \\
0.002432^{* *} \\
0.008494^{* *}\end{array}$ \\
\hline
\end{tabular}

${ }^{*} p<0.05 ; * *<0.01, p>0.05$, not significant.

Research hypothesis: Warmer temperatures enable higher rate of regeneration compared to colder temperatures.

Null hypothesis: There is no difference in rate of regeneration with difference in temperature.

measurements were obtained, and the average value was recorded for the length of fin rays 2 and 3. Fin rays 2 and 3 were defined as the second and third bony fin ray from the bottom plane of the amputated fin. Fin ray 3 measurements revealed an overall increase in growth with increasing temperature at each time point examined (Fig. 2B). Similar results were obtained for fin ray 2 (not shown). Similar to the total area measurements, significant increases in regeneration was only consistently seen between RT or $28^{\circ} \mathrm{C}$ and $30^{\circ} \mathrm{C}$ (Table 1). When analyzing the daily rate of regeneration using specific fin rays, an interesting pattern was revealed. Initially, as with the total area rates, the fish in $30^{\circ} \mathrm{C}$ water had a very high rate of growth in the first 2 days. For example, in fin ray 2 for the first 2 days, the fish in $30^{\circ} \mathrm{C}$ water had an average daily rate of $29.81 \mu \mathrm{m} /$ day as compared to $21.66 \mu \mathrm{m} /$ day and $10.59 \mu \mathrm{m} /$ day at $28^{\circ} \mathrm{C}$ and $\mathrm{RT}$, respectively (Table 2). However, by day 6 , the fish in $30^{\circ} \mathrm{C}$ water maintained a steady daily rate of growth $(30.29 \mu \mathrm{m} /$ day $)$, while the daily rates of outgrowth at the lower temperature seemed to rebound, reaching $27.94 \mu \mathrm{m} /$ day at $28^{\circ} \mathrm{C}$ and $22.45 \mu \mathrm{m}$ /day at RT (Table 2). A similar trend was seen in fin ray 3.

\section{Effect of temperature on vascular regeneration}

Using the (TG(Fli1:EGFP)) transgenic zebrafish ${ }^{18}$ as a readout for blood flow and rate of blood supply in the regenerating fin, we were able to see that increased temperature resulted in more rapid regeneration of vasculature. The (TG(Fli1:EGFP)) transgenic line expresses Green Fluorescent Protein (GFP) in vascular endothelial cells. One adult (TG(Fli1:EGFP)) transgenic zebrafish was included with each cohort of experimental fish. Qualitatively, the students observed the rate of vascular formation between the three experimental temperatures. There was a dramatic increase in vascular structures in the higher temperatures (Fig. 4). This was useful as a discussion point and theorizing about why the fins are regenerating faster at higher temperatures.

\section{Discussion}

\section{Role of temperature on fin regeneration}

This laboratory exercise clearly supports the hypothesis that increased temperature will cause more rapid regeneration in zebrafish fins. Interestingly, most studies examining fin regeneration use temperatures $\left(30^{\circ} \mathrm{C}-33^{\circ} \mathrm{C}\right)$ that are higher than the normal zebrafish aquaculture conditions $\left(28.5^{\circ} \mathrm{C}\right) .{ }^{19,20}$ The last fin measurement was performed at $6 \mathrm{dpa}$, in part due to the fact that $6 \mathrm{dpa}$ was the day before the next scheduled laboratory session, and the plane of amputation becomes difficult to discern by $6 \mathrm{dpa}$, especially in the fish in $30^{\circ} \mathrm{C}$ water. The fins were measured on three separate days $(2,3$, and 6$)$ to provide a range of values for mathematical calculations. We were interested not only in the overall trends in total regeneration, but we also wanted the students to

Table 2. Average Rate of Regeneration per Day

\begin{tabular}{|c|c|c|c|c|c|c|c|c|c|c|c|}
\hline \multirow[b]{2}{*}{ Fin ray 2} & \multicolumn{3}{|c|}{ Rate of regeneration } & \multirow[b]{2}{*}{ Fin ray 3} & \multicolumn{3}{|c|}{ Rate of regeneration } & \multirow[b]{2}{*}{ Area } & \multicolumn{3}{|c|}{ Rate of regeneration } \\
\hline & Day 2 & Day 3 & Day 6 & & Day 2 & Day 3 & Day 6 & & Day 2 & Day 3 & Day 6 \\
\hline RT & 7.061 & 17.72533333 & 22.45233 & RT & 10.665 & 18.97333 & 22.185 & RT & 21544.8 & 31175.67 & 45742.9 \\
\hline $28^{\circ} \mathrm{C}$ & 21.66 & 20.62333333 & 27.94167 & $28^{\circ} \mathrm{C}$ & 17.765 & 20.24333 & 26.715 & $28^{\circ} \mathrm{C}$ & 30323.67 & 35306.67 & 46640.6 \\
\hline $30^{\circ} \mathrm{C}$ & 4.81 & 27.77333333 & 30.29667 & $30^{\circ} \mathrm{C}$ & 28.77 & 29.15667 & 30.13333 & $30^{\circ} \mathrm{C}$ & 57179 & 61165.67 & 66097.6 \\
\hline
\end{tabular}

The daily rate of regeneration was calculated using the following equation: rate=area2-area1/time2-time1.

Values are displayed as average per day from previous measurement value. The fin ray length rates reflect a similarity in rates as time proceeded, whereas the overall area did not appear to level out between the three temperatures. 
Day 2

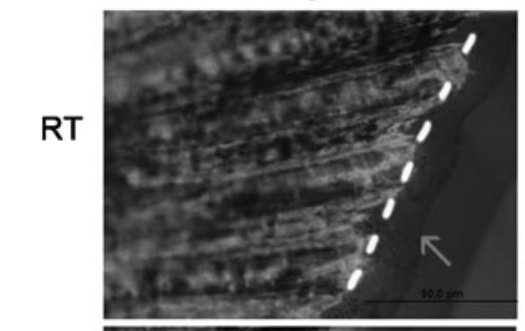

$28^{\circ} \mathrm{C}$
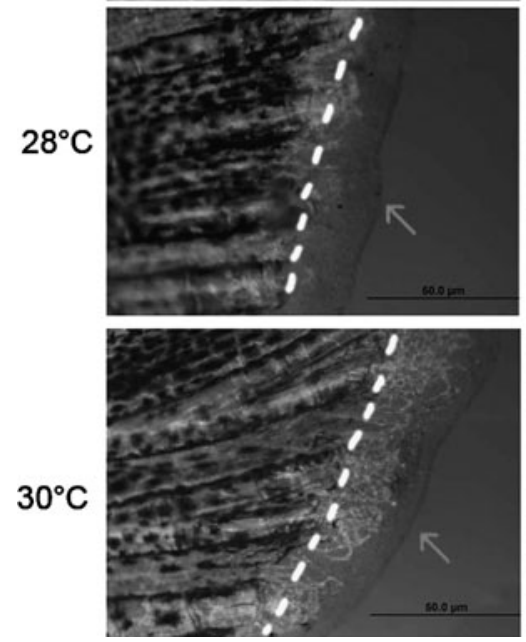

Day 3
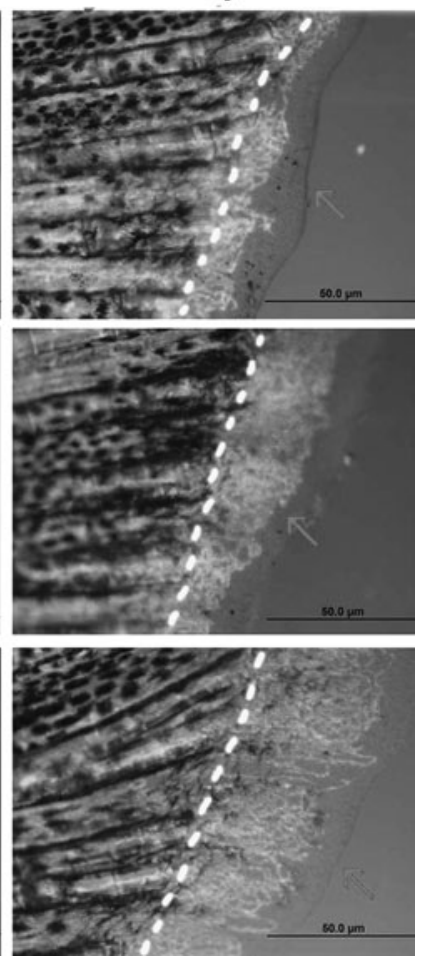

FIG. 4. The (TG(Fli1:EGFP)) transgenic line in which green fluorescent protein (GFP) is expressed in endothelial cells of the newly formed vasculature in the regenerating fins. As soon as $2 \mathrm{dpa}$, there is significantly more vasculature regenerated from the plane of amputation (dotted line) at $30^{\circ} \mathrm{C}$ when compared to the $\mathrm{RT} / 28^{\circ} \mathrm{C}$ fish. By $3 \mathrm{dpa}$, the vasculature in the $30^{\circ} \mathrm{C}$ fish has expanded to the outermost edge of the regenerated tissue, whereas the $\mathrm{RT} / 28^{\circ} \mathrm{C}$ fish still have a significant amount of regenerated fin tissue without endothelial cell differentiation; dpa, days post amputation. calculate actual rates of "regeneration/day." Additionally, having the students measure multiple days provides a realistic experimental design which was also a major goal of this exercise. We included measurements of individual fin rays to determine any potential skewed results from total fin area due to inexperienced fin amputation and variability in the plane of amputation. We wanted to compare length of ray growth that we hypothesized would be less variable than total area. No conclusions could be drawn regarding the best measurement for this activity (Table 1). However, it would seem that measuring fin ray 2 is not as useful as fin ray 3 , as fin ray 3 had a $p<0.01^{* *}$ similar to values obtained for total area (Table 1 ).

\section{Analysis of educational outcomes}

Goal 1: Promote student-led design of experiments to test factors that may impact the rate of fin regeneration. The choice to examine the role of heat on fin regeneration was made by the students in the Bioengineering 101 laboratory at The University of Massachusetts Dartmouth. This exercise followed the enzyme kinetic laboratory as described above. After a presentation outlining the concepts of fin regeneration, students broke out into working groups to design research proposals using measurable experiments with the fin model. This laboratory section enrollment was 24 students, and break-out groups were limited to 3 students to ensure participation. The proposals were peer-reviewed and the highest scoring proposal was selected for the group's experiment. This discussion in and of itself was enlightening. For example, the temperature experiment received the highest scores most likely because they were better developed proposals, due to the fact that this is a topic that has been addressed in the research community in published data. Also, as this was a freshmen course, we were not surprised that the students chose to develop proposals that examined factors within their current knowledge base, and for these students the enzyme activity that preceded this lab discussed temperature and $\mathrm{pH}$. In discussing tissue engineering and bioreactor design, the students were also familiar with temperature, $\mathrm{pH}$, and media (or nutrients) when thinking about how cells can grow and divide. The novel proposal topics of sex and stress were interesting because those two groups considered more systemic issues and just not cell function. The sex proposal was the second highest in score, and from discussion this seemed to be due to the fact that it was an easily controlled variable. The students were able to define 3-4 separate feeding conditions, and ideas of how to make some water healthier than others. The students also identified potential limitations in controlling the feeding (i.e., not knowing if fish ate equally within a tank), and several students were not in favor of potentially making the fish "sick" by altering $\mathrm{pH}$ and nitrate concentration. We needed to limit this activity to one choice due to the space limitations. Over time we hope to acquire more individual aquaria and allow 2-3 different conditions to be tested. We rated the outcome of this goal as highly successful due to the amount of discussion and ownership generated for this experiment. End of semester evaluations were used to survey the variety of labs we used in this freshman level course. The evaluation of this lab revealed equal impact of the proposal exercise and the multiple days of data collection in regards to students feeling investment and/or ownership of this experiment (Fig. 5).

Goal 2: Student participation in multiple days of data collecting mimicking actual experiments in research laboratories. A major goal of this laboratory exercise was to expose the students to the rigor of actual data collection and responsibility when conducting experiments. This is lacking in many modular laboratory exercises, students that only 


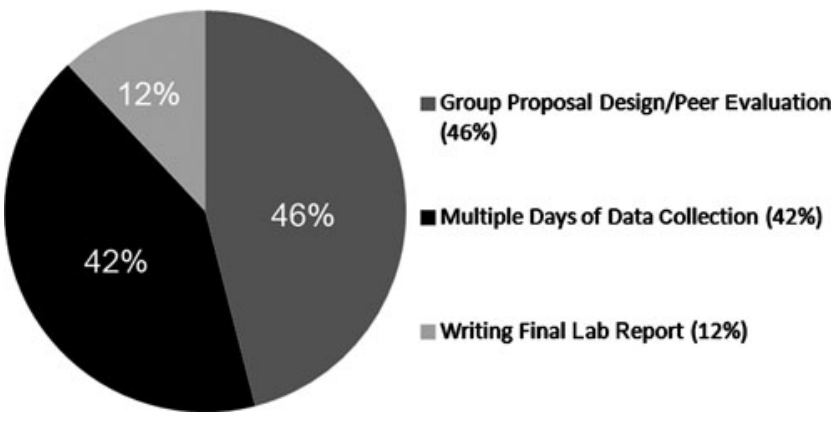

FIG. 5. Class evaluation results for the question asking "Which component of this lab promoted ownership/interest in the project the most?" All 24 students answered and each option represented as a percent. The proposal activity and multiple days of data collection rated very similarly.

have to participate for a defined 2-3 hour block do not gain exposure to how actual laboratory work proceeds. Therefore, we scheduled students to record temperature throughout the week, and each student had assigned times to measure two fish and capture images. This was the most challenging component of this exercise due to class and teaching schedules. Capturing each image allowed later measurements during a regularly scheduled lab session. During the second regularly scheduled weekly lab session, each student was assigned three specific fish to measure fin rays and total area using Image-J. This number was calculated to cover 24 students measuring all fish. In total, there were 648 measurements recorded in the class DATA Excel file. Assigning three fish to each student provided adequate experience for each student with Image-J, and all data could be collected in one laboratory session. Additionally, having the students gather three replicate measurements and calculating an average demonstrated the need for rigor in measurements and ensuring accurate values through reproducibility. Course evaluations revealed that students saw this data collection requirement as a positive impact on their investment in the experiment (Fig. 5). Also, the evaluations revealed that the more a student participated in data collection throughout the week, the more successful they were in putting together the final lab report (Fig. 6). Determining a "critical" amount of involvement for this activity was difficult but the evaluation indicated that students who participated in four out of the six sessions all scored above $80 \%$ on their report; this meant that they participated minimally in one fin measurement time point outside of assigned class time. They were required to measure regeneration minimally at one time point, therefore lack of participation in all six sessions was not a component of the rubric, rather is seen as an inferred advantage and a higher level of commitment when students did participate in additional sessions.

Goal 3: Thorough presentation of the experiment in the form of a written report. The students enrolled in this course possessed variable educational backgrounds, with the exception of three students; they were all first semester freshmen and recent high school graduates. We took the approach with this assignment that students would generate their first report and then have the chance to revise. This approach allowed for a one-on-one discussion regarding specific weaknesses of a student's report. The requirements for the report were as follows: Abstract, Introduction (based on at least one research article about fin regeneration, as well as in class discussions), Materials and Methods, Results, Discussion, Conclusion, and References (Grading Rubric, Appendix 2). Requirements for the results section included: graphs showing the results of temperature over days, determining significance with statistical analysis, and calculation of actual rate of regeneration per day over the 6 days. The approach we took with this report was highly beneficial to the students who needed more individual guidance, as we were able to help them identify weaknesses in their own work and not merely lecture to the whole group. The most consistent weakness for the students

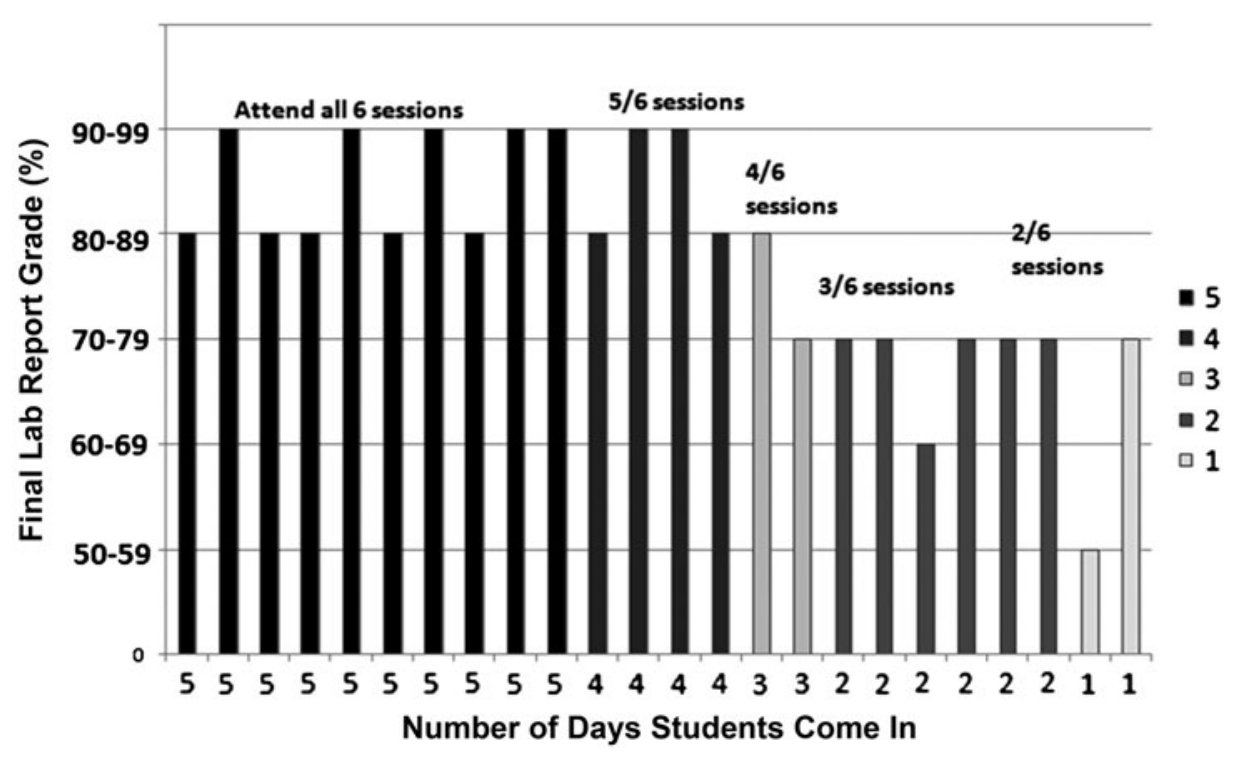

FIG. 6. Student final lab report grades in relation to how many days the student participated in the lab activities. Students were expected to attend four of the six sessions. This included only one measurement time point. Final lab report scores were independent of participation. However, the scores increase with increased participation in class activities. 
was in generating the correct graph (Appendix 3). Typically, students did not place the correct values in the $\mathrm{x}$ and $\mathrm{y}$ axis, which resulted in a graph that did not demonstrate to the reader how rates increased over time. The problems with the introduction were that they were too brief and often did not cite sources thoroughly and the citations were poorly formatted. As we build on this first semester science major course, we have designed assessments to ensure program outcomes are met. The foundation of this lab report will be built upon in sophomore through senior level courses. With individual tutoring by the professor and the doctoral student teaching assistant, we were able to help students make better choices in their revision. Discussion points generated by the students included discussing how increased vasculature seen in the GFP fish may have promoted more rapid wound healing. The students were even able to suggest that the initial dramatic rate seen at $30^{\circ} \mathrm{C}$ in the fin rays may have indicated faster wound healing, which happens in Day 1, which may have resulted in faster initial outgrowth. They did note that by the end it appeared that rates became more equal, indicating something significant happening in those first 2 days at the higher temperature.

Goal 4: Impact of vertebrate research on science and appropriate handling of animals. The zebrafish offer a great platform for discussions of animal use in research. There is low risk to the animal with a fin regeneration procedure but the students still have empathy for the animals. The student training module introduces them to the rigor of oversight for animals. Furthermore, the act of amputating the fin and taking certain responsibility that the animal awakens has high impact on the students in maintaining compassion for test subjects. Most fish had gill movement upon return to the water. However, due to the need for a deeper level of sleep for the imaging steps, a few fish did require resuscitation. The student simply flushed water through the gills with a transfer pipette to resuscitate the fish. This resuscitation was very interesting to the students when it was necessary. The students were evaluated on their understanding of animal use through exam questions. For example, they were expected to define key IACUC concepts: Replace, Reduce and Refine, and give an example of how each would be applied when considering the fin regeneration experiment. This animal training was an introduction to our program outcome of "understanding professional and ethical responsibility." A sophomore level course will address power analysis, compliance issues, and design of experiments, with more rigor as the student progresses through the program. Additional evaluation of the success of this goal could also involve a pre/post reflective writing assignment.

The lab activities in this Bioengineering 101 course vary dramatically. Several lab activities teach practical skills in using equipment and some activities are hypothesis driven, focusing on the scientific method. For example, students learn to operate spectrophotometers, perform tensile strength testing on various fibers, develop a pumping heart-like structure and measure pressure, as well as enzyme kinetics and the tissue regeneration activity. Both skill sets are required in our students for upper level courses, and each address specific learning outcomes. Each of the eight lab topics were evaluated by students at the end of semester on the course evaluations form. This lab was rated highest on the following topics: "reinforce- ment of scientific method," "taught student how to assemble concepts into a final experimental design," "gave experience in following through on a long-term research question," and this lab activity rated high as well for "allowed for creation of an experiment from their own ideas," and that "teamwork was important on this project." On the other hand, this topic rated very low on criteria such as "learning an important technique" or being "taught to solve a technical problem with equipment." This laboratory exercise has been developed targeting several program educational objectives. The concepts introduced in this course serve as a foundation for advanced courses. Specifically, this lab addresses student outcomes that fall into the following categories: 1 . An ability to design and conduct experiments; 2. An ability to function on teams; 3. An understanding of professional and ethical responsibility; and 4. An ability to communicate effectively. Each of these program objectives is relevant to most science programs, making this a useful educational exercise for numerous course topics.

\section{Alternative activities analyzing fin regeneration}

This exercise is meant to provide an introduction to teachers regarding the usefulness of fin regeneration as a laboratory module. As we have seen in the zebrafish education issue, the zebrafish can be used in numerous types of laboratory courses. In addition to this introductory bioengineering course, we have utilized fin regeneration in an upper level developmental biology laboratory, although the peer reviewed proposal activity was new to this freshman level course. Different chemical agents can be supplemented into the water to examine the effect on regeneration, as we showed inhibiting depolymerization of the cytoskeleton with nocodazole. ${ }^{21}$ We did briefly examine the role of "healthy water" on fin regeneration in a short summer course where one tank of fish was kept on the re-circulating system where waste did not accumulate as it does in small table top aquaria. The area of regeneration of the $28.5^{\circ} \mathrm{C}$ tabletop fish was compared to the same $28.5^{\circ} \mathrm{C}$ system fish. Interestingly, we did notice more regeneration in the system fish, suggesting overall health and water quality may also impact regeneration.

\section{Acknowledgments}

The authors wish to acknowledge the UMD bioengineering class of 2015 for their participation and feedback regarding this exercise, as well as the students from the UMD College of Engineering 2011 Freshman Summer Institute (FSI) for their initial execution of this activity. We would also like to thank Dartmouth High School senior Gina Georgadarellis for performing an independent trial of this exercise during her internship at UMD, and UMD Bioengineering major Nick Macedo for review of the manuscript.

\section{Disclosure Statement}

No competing financial interests exist.

\section{References}

1. Experiential Learning \& Experiential Education: Philosophy, Theory, Practice \& Resources. Available at http://wilderdom .com/experiential/, accessed May 6, 2010.

2. Minner DD, Levy AJ, Century J. Inquiry-based science instruction-What is it and does it matter? Results from a 
research synthesis years 1984 to 2002. J Res Sci Teaching 2010;47:474-496.

3. Gilbert SF. Developmental Biology, 9th edition. Sinauer Associates, Inc., Sunderland, MA, 2010.

4. Naderi H, Matin MM, Bahrami AR. Critical issues in tissue engineering: Biomaterials, cell sources, angiogenesis, and drug delivery systems. J Biomat Appl 2011;26:383-417.

5. Korossis SA, Bolland F, Kearney JN, Fisher J, Ingham E. 2005. Bioreactors. In: Topics in Tissue Engineering: VIII: Volume 2. N. Ashammakhi, R.L. Reis, eds.

6. Nakitani Y, Kawakami A, Kudo A. Cellular and molecular processes of regeneration, with special emphasis on fish fins. Devel Growth Diff 2001;49:145-154.

7. Iovine MK, Johnson SL. Genetic analysis of isometric growth control mechanisms in the zebrafish caudal fin. Genetics 2000;155:1321-1329.

8. Whitehead GG, Makino S, Lien CL, Keating ML. $f g f 20$ is essential for initiating zebrafish fin regeneration. Science 2005;310:1957-1960.

9. Poss KD, Keating MT, Nechiporuk A. Tales of regeneration in zebrafish. Dev Dyn 2003;226:202-210.

10. Johnson S, Weston J. Temperature sensitive mutations that cause stage-specific defects in zebrafish fin regeneration. Genetics 1995;141:1583-1595.

11. Tal TL, Franzosa JA, Tanguay RL. Molecular signaling networks that choreograph epimorphic fin regeneration in zebrafish. A mini-review. Gerontology 2010;56:231-240.

12. Brittijn SA, Duivesteijn SJ, Belmamoune M, Bertens LF, Bitter W, de Bruijn JD, et al. Zebrafish development and regeneration: New tools for biomedical research. Int J Dev Biol 2009;53:835-850.

13. Yin VP, Poss KD. New regulators of vertebrate appendage regeneration. Curr Opin Genet Dev 2008;18:381-386.
14. Akimenko MA, Marí-Beffa M, Becerra J, Géraudie J Akimenko. Old questions, new tools, and some answers to the mystery of fin regeneration. Dev Dyn 2003;226:190-201.

15. Westerfield M. The Zebrafish Book. University of Oregon Press, Eugene, OR, 1995.

16. Poss KD, Shen J, A. Nechiporuk JA, McMahon G, Thisse B, Thisse C, Keating M. Role for Fgf signaling during zebrafish fin regeneration. Dev Biol 2000;222:347-358.

17. Tseng AS, Levin M. Tail regeneration in Xenopus laevis as a model for understanding tissue repair. J Dental Res 87;806816:2008.

18. Lawson ND, Weinstein BM. In vivo imaging of embryonic vascular development using transgenic zebrafish. Dev Biol 2002;248:307-318.

19. Thomas JL, Ochocinska MJ, Hitchcock PF, Thummel R. Using the Tg (nrd: egfp)/albino zebrafish line to characterize in vivo expression of neurod. PLoS ONE 2012; 7:e29128.

20. Lee Y, Grill S, Sanchez A, Murphy-Ryan M, Poss KD. Fgf signaling instructs position-dependent growth rate during zebrafish fin regeneration. Development 2005;132:5173-5183.

21. Hassoun L, Hable W, Payne-Ferreira TL. Tissue regeneration in the classroom. Am Biol Teacher 2008;70:530-532.

Address correspondence to: Tracie L. Ferreira, Ph.D. Department of Bioengineering University of Massachusetts 285 Old Westport Road North Dartmouth, MA 02747

E-mail: tferreira@umassd.edu 
Appendix 1. Detailed Group Proposal Guidelines, and Grading Rubric as Well as the Score Sheet and Scoring Rubric for the Peer Review of Proposals

\section{Fin Regeneration Group Research Proposal Guidelines}

1. Meet as a group throughout the next week and brainstorm ideas about what you can test as having an effect on tissue regeneration in the fish.

2. Goal: To generate a testable hypothesis and a research plan for the class to evaluate.

3. Research Plan outline.

(50 pts) Introduction: 1-2 page summary of the key concepts regarding zebrafish fin regeneration from lecture and any outside sources you find. This can feed into your final lab report regardless of which proposal is "Selected."

(15 pts) Hypothesis and Impact: What specifically will you test and why should we test it? In other words, if you want the class to commit time and resources, will we find out something important from your experiment (see your idea and its relevance). This section should also present your predictions about what will happen.

(20 pts) Experimental Design: Outline what you want to test and how you will do it. How many animals, conditions to test, what data to collect etc.

(15 pts) Summary statement: Bring us back to a brief paragraph summary of what you will do, why you want to do this and what important results will come from this.

Submit a single document with your group number in the top right corner, and next lab session we will have a peer review session and score the proposals according to the guidelines on the next page. Each proposal will be scored by 3 other groups, as a whole class we will discuss the results and select which experiment we will do based on highest score and our whole group discussion.

\section{Peer Review Rubric for Research Proposals}

As a group, score each proposal on the following components.

1. Not well developed

2. Good start but needs some added work

3. Generally OK but not top $25 \%$

4. Very strong, minor changes would be good but overall top $10 \%$

5. Excellent, no serious things to fix, overall top 5\%

Required to add comments to each section to help the group learn what might have made the proposal better in your eyes.

Remember: Proposals are scored based on how good they are compared to other proposals that a reviewer has read over a lifetime, so there is some value to how this compares to the others you are reading. You are basically finding the "strongest" proposal while acknowledging that the proposals all have merit and how they could become stronger.

1. The proposed work will answer an important question and provide valuable data. (Significance)

$\begin{array}{lllll}1 & 2 & 3 & 4 & 5\end{array}$

Comments:

2. The proposed work can be performed in the time allowed and with the resources available. (Environment) $\begin{array}{lllll}1 & 2 & 3 & 4 & 5\end{array}$

Comments:

3. The students have the skills needed to perform this experiment. (Investigator)

$\begin{array}{llllr}1 & 2 & 3 & 4 & 5\end{array}$

Comments:

4. The experiments outlined will answer the hypothesis posed by the group. (Approach)

$\begin{array}{lllll}1 & 2 & 3 & 4 & 5\end{array}$

Comments:

Total overall numerical score (add the 4 sections) 
Appendix 2. Zebrafish Fin Regeneration Lab Report Grading Rubric

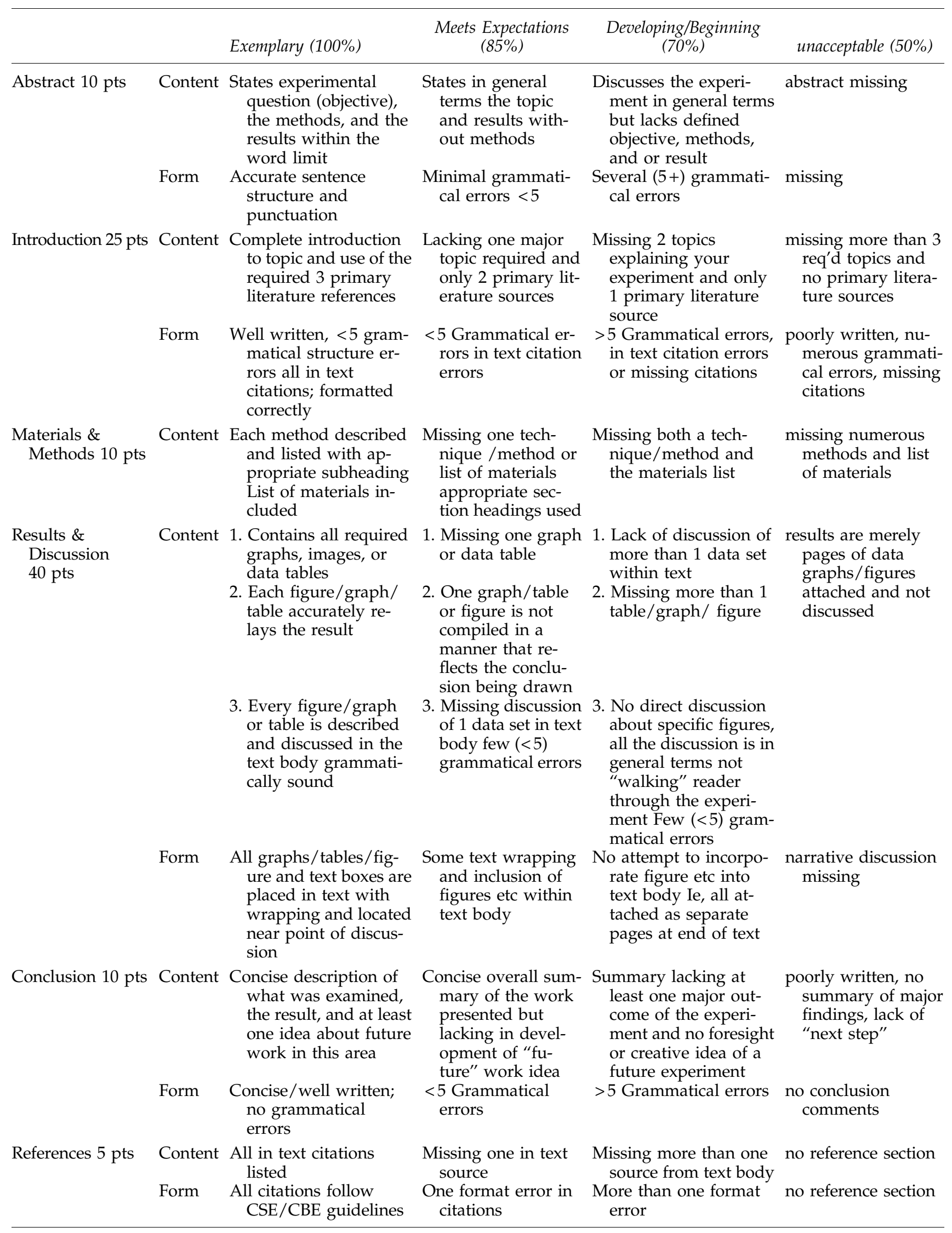


Appendix 3.

A1
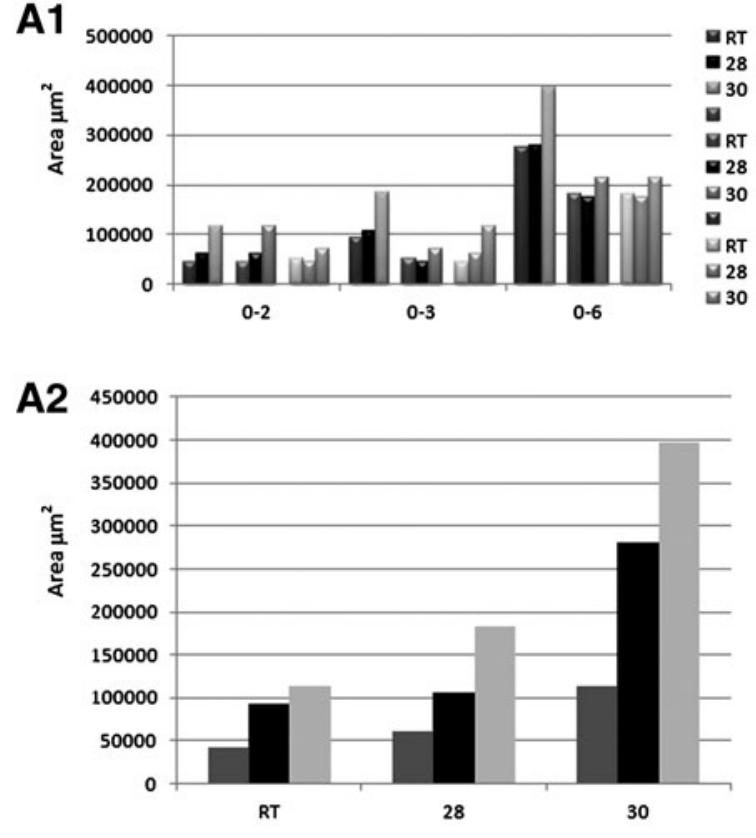

A3

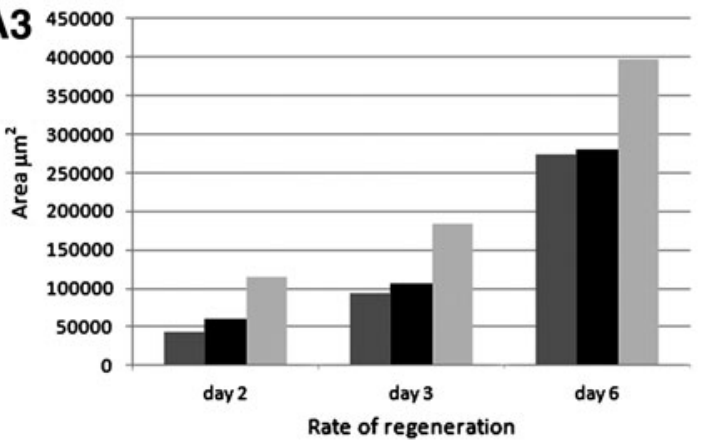

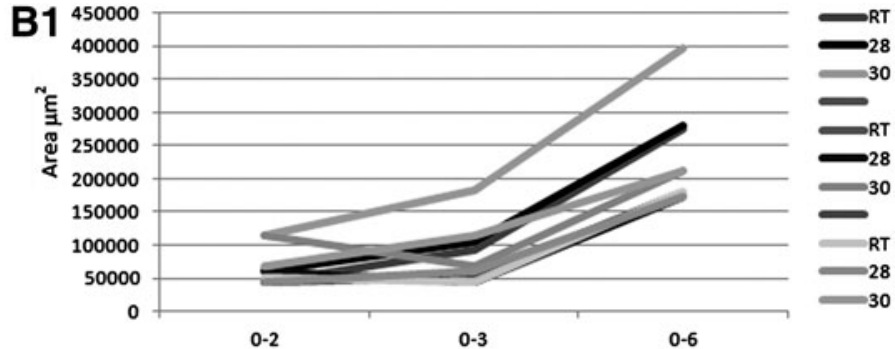

B2
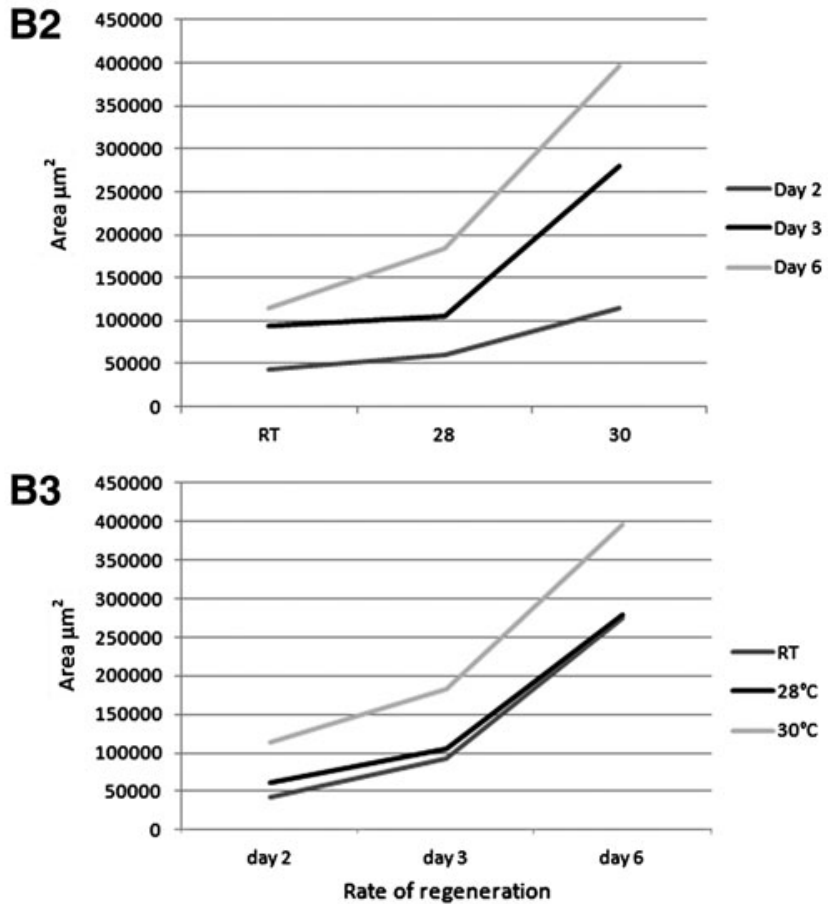

APPENDIX 3. Examples of poorly formatted bar graphs and line graphs from students work. Each column A or B begins with the initial submission A.1/B.1 and progresses to final acceptable graphs representing the data more clearly (A.3/B.3). We found that students did not format the Excel sheet columns correctly to generate graphs that truly illustrated the results supported by their data. 